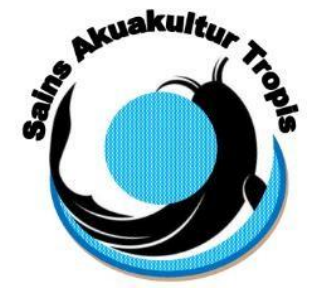

\author{
Jurnal Sains Akuakultur Tropis \\ De part e m e n A u a u t u r \\ Fakultas Perikanan dan IImu Kelautan - Universitas Diponegoro \\ JI. Prof. Soedarto, SH, Tembalang, Semarang 50275 \\ Telp. (024) 7474698, Fax.: (024) 7474698
}

Email: sainsakuakulturtropis@gmail.com, sainsakuakulturtropis@undip.ac.id

\title{
PENGARUH TINGKAT KEPADATAN TELUR YANG BERBEDA TERHADAP EMBRIOGENESIS, LAMA WAKTU PENETASAN DAN DERAJAT PENETASAN TELUR IKAN TAWES \\ (Barbonymus gonionotus)
}

\author{
The Effect of Different Egg Density Levels on Embryogenesis, Hatching Time and \\ Hatching Rate of Tawes Fish Egg (Barbonymus gonionotus)
}

Ziadah Alfath, Fajar Basuki*, Ristiawan Agung Nugroho

Departemen Akuakultur

Fakultas Perikanan dan Ilmu Kelautan, Universitas Diponegoro

J1. Prof. Soedarto SH, Tembalang, Semarang - 50275

\begin{abstract}
ABSTRAK
Proses penetasan telur merupakan salah satu fase yang menentukan keberhasilan budidaya ikan. Daya tetas telur yang tinggi dengan kualitas telur yang baik akan menjadikan produksi larva tawes dengan kualitas yang baik. Permasalahan dari produksi dalam budidaya ikan tawes hanya mampu menghasilkan telur sebanyak 10.000 dengan daya tetas yang rendah yaitu sebesar $22 \%$. Sebagai upaya peningkatan derajat penetasan telur ikan tawes yaitu dengan perlakuan tingkat kepadatan yang berbeda pada setiap wadah penetasan. Penelitian ini bertujuan untuk mengetahui pengaruh tingkat kepadatan yang berbeda terhadap perkembangan telur dan derajat penetasan telur ikan tawes (B.gonionotus), untuk mengetahui kepadatan yang optimal bagi penetasan telur ikan tawes. Penelitian dilaksanakan Satuan Kerja Perbenihan dan Budidaya Ikan Air Tawar (PBIAT) Ngrajek, Magelang, Jawa Tengah pada Bulan Maret-April 2018. Bahan uji yang digunakan adalah telur ikan tawes (B.gonionotus) hasil pemijahan di Balai. Penelitian ini menggunakan metode eksperimental dengan Rancangan Acak Lengkap (RAL) terdiri atas 4 perlakuan dengan 3 kali ulangan yakni, kepadatan dalam 10 liter air A (10 butir/liter air), B (20 butir/liter air), C (30 butir/liter air), D (40 butir/liter air). Variabel yang diukur meliputi: Pengamatan perkembangan telur secara deskriptif, waktu penetasan (menit), derajat penetasan (HR) dan kualitas air. Data derajat penetasan dianalisis dengan analisis ragam, apabila berpengaruh maka dilakukan uji wilayah ganda Duncan untuk mengetahui beda antar perlakuan untuk menentukan perlakuan terbaik. Hasil penelitian menunjukkan bahwa tingkat kepadatan yang berbeda berpengaruh nyata ( $\mathrm{F}$ hitung $>\mathrm{F}$ tabel) terhadap parameter uji. Hasil perkembangan embrio tercepat diperoleh perlakuan $\mathrm{C}$ dan $\mathrm{D}$ secara bersamaan, derajat penetasan tertinggi diperoleh perlakuan B yaitu sebesar $89,83 \pm 3,55$.
\end{abstract}

Kata kunci : ikan tawes; embriogenesis; derajat penetasan

\section{ABSTRACT}

The process of hatching eggs is one phase that determines the success of fish farming. High egg hatchability with good egg quality will make good quality larvae production. The problem of production in Tawes fish cultivation is only able to produce as many as 10,000 eggs with a low hatchability of 22\%. As an effort to increase the degree of hatching of Tawes fish eggs, which are different treatment levels in each hatchery. This study aims to determine the effect of different density levels on egg development and the degree of hatching of Tawes fish eggs (B.gonionotus), to determine the optimal density for hatching rate of Tawes fish eggs. The research 


\section{Z.Alfath, F. Basuki, R.A. Nugroho/Jurnal Sains Akuakultul Tropis:4(2020)2:129-138 eISSN:2621-0525}

was carried out the Freshwater Fish and Aquaculture Work Unit (PBIAT) of Ngrajek, Magelang, Central Java in March-April 2018. The test material used was Tawes fish (B.gonionotus) from spawning at here. This study used an experimental method with a completely randomized design (CRD) consisting of 4 treatments with 3 replications namely, density in 10 liters of water A (10 grains / liter of water), B (20 grains / liter of water), C (30 grains / liter of water), D (40 grains / liter of water). The variables measured included: descriptive egg development observations, hatching time (minutes), hatching rate (HR) and water quality. Hatching rate data were analyzed by variance analysis, if it was influential, Duncan's multiple region test was conducted to determine the differences between treatments to determine the best treatment. The results showed that different levels of density had a significant effect (Fcount $>F$ table) on the test parameters. The fastest result of embryo development was $C$ and $D$ treatment simultaneously, the highest hatching rate was obtained by treatment $B$, which was $89.83 \pm 3.55$.

Key words: Tawes fish; embryogenesis; hatching rate

*Corresponding author: fbkoki2006@yahoo.co.id

\section{PENDAHULUAN}

Ikan tawes merupakan salah satu komoditas ikan air tawar di Indonesia yang semakin diminati. Ikan tawes (B. gonionotus) atau dikenal dengan nama tawas atau lampam menurut Hanief et al., (2014), merupakan salah satu ikan budidaya air tawar asli indonesia. Ikan tawes merupakan salah satu ikan yang bersifat herbivora sehingga menguntungkan bagi pembudidaya tradisional. Penggunaan ikan tawes sebagai ikan uji juga dikarenakan ikan tawes merupakan ikan endemik yang harus dibudidayakan. Selain itu juga untuk mengetahui proses pemijahan dan perkembangan telur ikan tawes untuk mengetahui tingkat derajat penetasan telur dan kelulushidupan larva ikan tawes.

Proses penetasan telur dan kelulushidupan larva merupakan salah satu faktor penting dalam pembenihan ikan. Upaya dan penanganan pemeliharaan telur yang baik akan menghasilkan larva dengan tingkat mortalitas yang rendah. Menurut Sinjai (2011), masalah terbesar yang dihadapi pembenihan ikan selama ini adalah tingginya angka kematian pada penetasan telur, sehingga perlu dilakukan cara untuk meningkatkan derajat pembuahan, daya tetas dan daya rekat telur ikan. Upaya peningkatan derajat penetasan telur ikan tawes yaitu dengan perlakuan tingkat kepadatan yang berbeda pada setiap wadah penetasan telur ikan tawes.

Proses penetasan telur merupakan salah satu fase yang menentukan keberhasilan budidaya ikan tawes. Daya tetas telur yang tinggi dengan kualitas telur yang baik akan menjadikan produksi larva tawes dengan kualitas yang baik. Permasalahan dari produksi dalam budidaya ikan tawes hanya mampu menghasilkan telur sebanyak 10.000 dengan daya tetas yang rendah yaitu sebesar 22\%. Kendala tersebut merupakan suatu permasalahan yang menghambat proses produksi benih ikan tawes sehingga diperlukan teknik pembenihan yang dapat meningkatkan daya tetas ikan tawes (Agustin dan Boedi, 2013).

Penanganan yang optimal untuk menghasilkan larva ikan tawes yang berkualitas yaitu dengan tingkat penetasan telur yang tinggi. Rendahnya ketersediaan benih ikan disebabkan antara lain daya tetas telur yang masih rendah menurut Hepher dan Pruginin (1981), peningkatan kepadatan telur ikan akan diikuti dengan penurunan pertumbuhan sehingga pada kepadatan tertentu pertumbuhan akan terhenti karena telah mencapai titik maksimal. Peningkatan padat penebaran akan diikuti dengan penurunan kualitas air. Pemeliharaan telur ikan yang kurang tepat akan berakibat pada proses perkembangan telur yang dihasilkan. Proses penetasan banyak faktor- faktor yang mempengaruhi berhasil tidaknya telur-telur ikan menetas secara normal Menurut Sugihartono (2013), kepadatan telur dalam suatu media penetasan dianggap berpengaruh terhadap kualitas air media dan daya tetas telur. Kepadatan telur yang tinggi berpeluang mempersempit ruang gerak embrio dan persaingan dalam mengkonsumsi oksigen $\left(\mathrm{O}_{2}\right)$, serta menurunkan kualitas air.

Penggunaan kepadatan yang berbeda pada penetasan telur ikan menurut Hepher dan Pruginin (1981) merupakan salah satu strategi penanganan untuk menghasilkan telur ikan tawes dengan daya tetas yang tinggi adalah pengaturan kepadatan dalam wadah dan masa inkubasi telur. Adanya kepadatan yang berbeda sebagai upaya mengetahui kepadatan yang optimal bagi embriogenesis dan derajat penetasan telur ikan tawes.

Kondisi lingkungan yang tidak menunjang (diluar kisaran optimal) seperti terlalu tinggi atau rendahnya suhu, adanya cahaya yang langsung dan lainnya, dapat mengakibatkan kematian terutama pada masa transisi atau kritis. Setiap organisme secara alamiah mempunyai kemampuan untuk menyesuaikan diri terhadap perubahanperubahan yang terjadi di lingkungannya dalam batas-batas tertentu atau di sebut tingkat toleransi. Jika perubahan lingkungannya terjadi di luar kisarannya toleransi suatu organisme, maka cepat atau lambat organisme tersebut 


\section{Z.Alfath, F. Basuki, R.A. Nugroho/Jurnal Sains Akuakultul Tropis:4(2020)2:129-138 eISSN:2621-0525}

akan mati. Kenaikan suhu yang masih dapat ditolerir oleh ikan akan di ikuti oleh peningkatan derajat metabolisme dan kebutuhan oksigen (Vladimirov, 1975).

\section{MATERI DAN METODE PENELITIAN}

Hewan uji yang digunakan dalam penelitian ini adalah telur ikan tawes (B. gonionotus.) yang berasal dari PBIAT Ngrajek Magelang. Induk ikan tawes dipijahkan secara semi alami. Ikan uji yang digunakan pada penelitian ini adalah telur ikan tawes yang baru menetas. Telur ikan uji langsung dipindahkan pada wadah penetasan berupa ember selama semalam sampai telur menetas. Wadah dalam ember dengan kepadatan 10, 20, 30 dan 40 butir telur/liter dengan volume air 10 liter. Selanjutnya dilakukan pengamatan perkembangan embrio ikan tawes dengan mikroskop setiap jam untuk mengetahui setiap fase perkembangan telur sampai dengan telur ikan tawes menetas.

Rancangan percobaan yang digunakan dalam penelitian ini adalah Rancangan Acak Lengkap (RAL) dengan 4 perlakuan dan 3 pengulangan. Adapun perlakuan penelitian ini adalah

Perlakuan A : Kepadatan 10 butir telur/ liter air

Perlakuan B : Kepadatan 20 butir telur/ liter air

Perlakuan C : Kepadatan 30 butir telur/ liter air

Perlakuan D : Kepadatan 40 butir telur/ liter air

Penelitian Sugihartono (2013), menyebutkan perlakuan yang digunakan untuk kepadatan telur ikan gurami yaitu 4, 8, 12, dan 16 butir/liter air dalam volume air 60 liter/wadah. Berdasarkan uraian literatur, perlakuan yang disesuaikan untuk telur ikan tawes yaitu dengan kepadatan 10, 20, 30 dan 40 butir/liter air dengan volume air berkisar 10 liter/wadah.

\section{Pengumpulan data}

Pengumpulan data yang dilakukan dalam penelitian ini meliputi data pengamatan perkembangan embrio (embriogenesis), waktu penetasan, derajat penetasan telur/hatching rate (HR) dan kualitas air.

a. Perkembangan embrio (embriogenesis)

Data pengamatan perkembangan embrio tawes meliputi deskripsi gambar perkembangan embrio perjam meliputi tiap fase perkembangan telur.

\section{b. Lama waktu penetasan}

Perhitungan lama waktu penetasan atau Hatching time telur dapat di hitung menggunakan rumus, yaitu selisih dari lama waktu akhir penetasan $(\mathrm{Ht})$ dengan waktu pasca panen $(\mathrm{H} 0)$ :

$$
\mathrm{HT}=\mathrm{Ht}-\mathrm{HO}
$$

\section{c. Hatching rate $(\mathrm{HR})$}

Derajat penetasan telur dapat dihitung dengan menggunakan rumus yang dikemukakan oleh Rustidja (1997) sebagai berikut :

$$
\operatorname{HR}(\%)=\frac{\text { Telur yang menetas }}{\text { Telur yang terbuahi }} \times 100 \%
$$

\section{d. Kualitas air}

Pengecekan kualitas air pada media penelitian meliputi beberapa parameter diantaranya suhu, oksigen terlarut (DO) dan derajat keasaman $(\mathrm{pH})$. Pengamatan kualitas air yang terdiri dari DO dan $\mathrm{pH}$ dilakukan pada pada awal dan akhir selama penelitian dan pengukuran suhu dilakukan setiap hari pada pagi dan sore hari.

\section{ANALISIS DATA}

Data embriogenesis ikan tawes di analisa secara deskriptif dengan gambar tiap fase perkembangan telur dilanjutkan dengan data lama waktu penetasan telur. Data kualitas air diukur sesuai dengan variabel yang di uji meliputi suhu, pH dan oksigen terlarut. Data derajat penetasan telur yang diperoleh terlebih dahulu diuji normalitas, uji homogenitas, dan uji additivas. Data tersebut harus memenuhi syarat menyebar secara normal, homogen, dan bersifat additiv. Selanjutnya data tersebut dianalisis ragam (uji F) dengan taraf kepercayaan $95 \%$. Apabila terdapat pengaruh nyata pada analisi ragam, selanjutnya dilakukan uji wilayah ganda Duncan untuk mengetahui perbedan nilai tengah rata-rata antar perlakuan, sedangkan data kualitas air dianalisis secara deskriptif dan dibandingkan dengan nilai kelayakan kualitas air pada budidaya ikan untuk mendukung pertumbuhan ikan (Srigandono, 1992). 


\section{HASIL DAN PEMBAHASAN}

HASIL

Perkembangan Embrio (Embriogenesis)

Hasil pengamatan perkembangan embrio dan lama waktu penetasan telur ikan tawes (B. gonionotus) tersaji pada Tabel 1. berikut ini:

Tabel.1 Embriogenesis Ikan Tawes dengan Kepadatan yang Berbeda

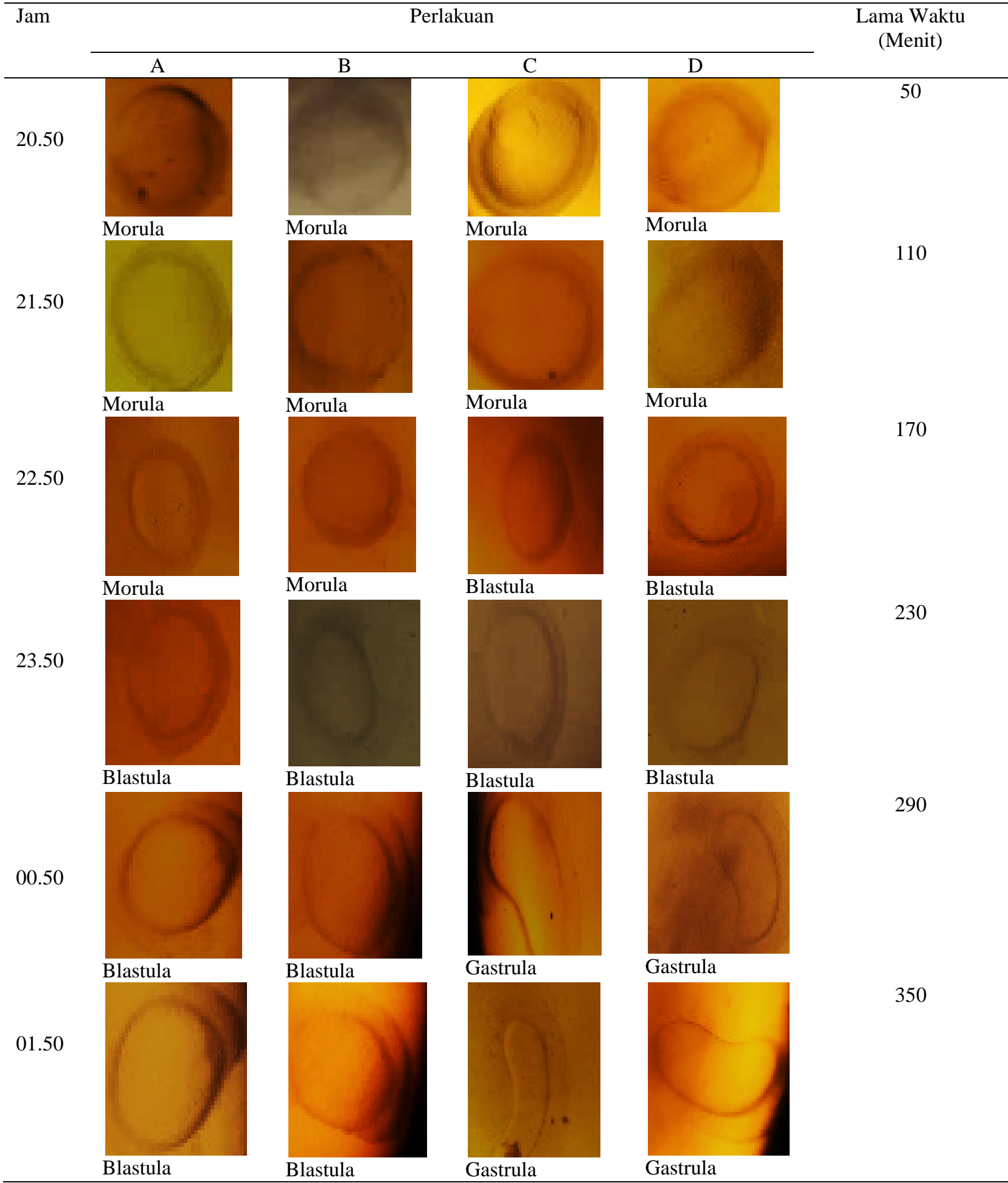




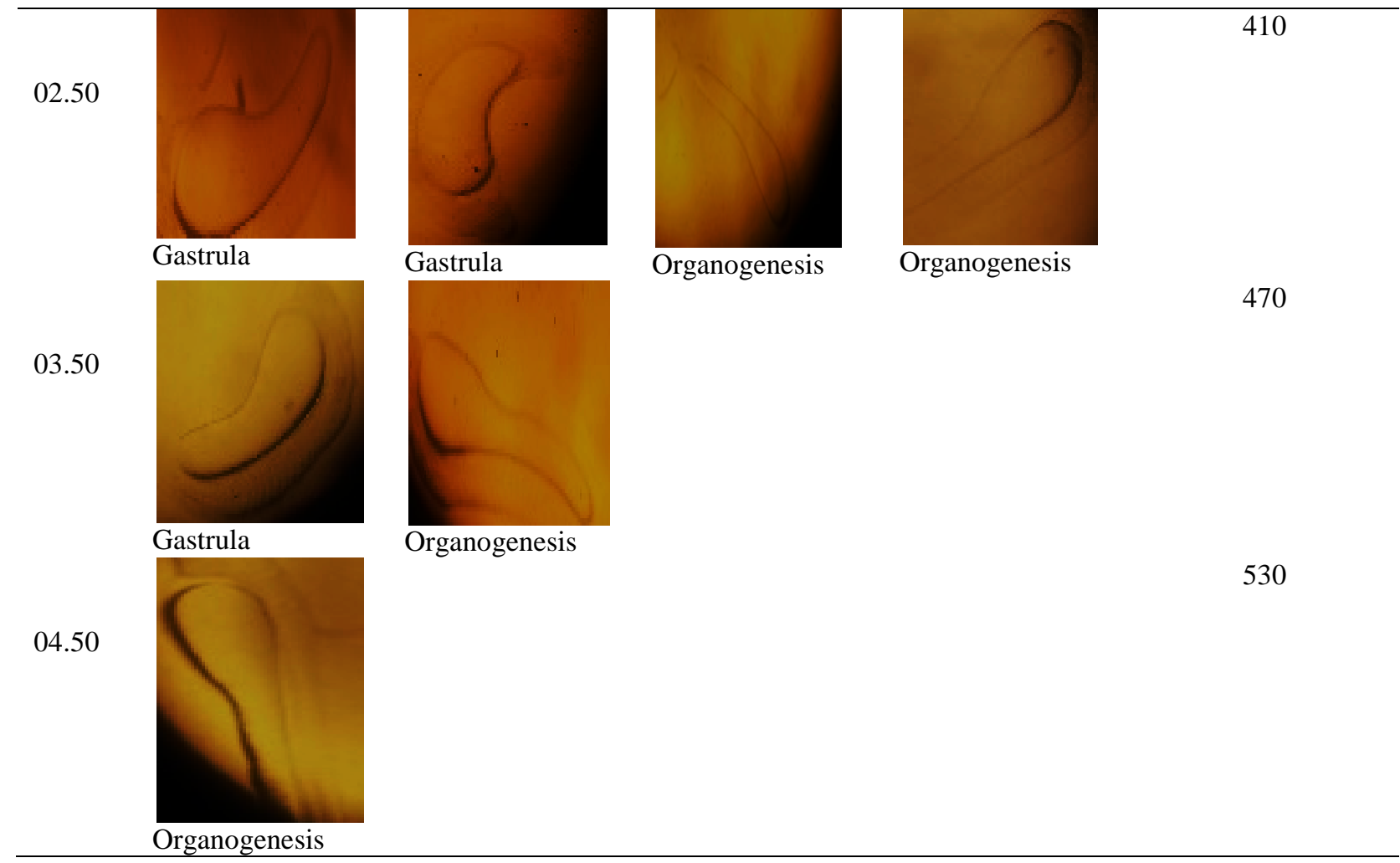

\section{Lama waktu penetasan}

Berdasarkan hasil perngamatan dan perhitungan lama waktu penetasan telur ikan tawes diperoleh data waktu penetasan tercepat secara bersamaan yaitu pada perlakuan C dan D. Setiap fase perkembangan telur antar perlakuan kepadatan memberikan hasil yang berbeda. Perlakuan C dan D dengan tingkat kepadatan yang tinggi didapatkan semakin cepat waktu yang dibutuhkan telur untuk menetas.

Awal perkembangan telur pertama didapatkan fase morula terjadi pada semua perlakuan di menit ke 50 sampai dengan menit ke 110. Memasuki menit ke 170 terlihat perbedaan pada perlakuan C dan D mulai memasuki fase Blastula, sementara untuk perlakuan A dan B tetap berada pada fase morula. Di menit ke 230 semua perlakuan mengalami fase yang sama yaitu fase blastula, dimana perlakuan A dan B memasuki fase blastula dan perlakuan C dan D secara bersamaan tetap berada di fase blastula. Menit ke 290 sampai dengan menit ke 350 untuk perlakuan A dan B tetap berada di fase Blastula, sementara untuk perlakuan C dan D memasuki fase perkembangan gastrula. Perkembangan telur mulai berbeda kembali di menit ke 410 dimana pada perlakuan C dan D telah berada pada fase organogenesis, sementara untuk perlakuan A dan B berada di fase gastrula. Di menit ke 470 perlakuan B telah mencapai fase organogenesis, dan perlakuan A mencapai fase organogenesis pada menit ke 530.

\section{Derajat Penetasan (HR)}

Berdasarkan hasil perhitungan derajat penetasan (HR) telur ikan tawes (B. goniotonus) diperoleh data rerata derajat penetasan telur (HR), berikut tersaji pada Gambar 1. berikut ini: 


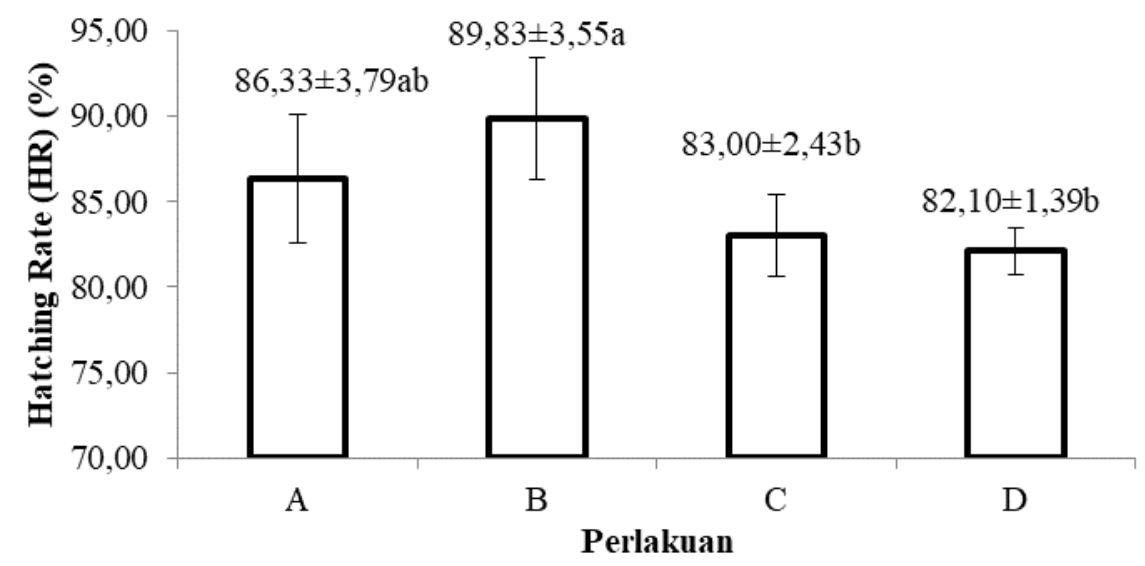

Gambar 1. Histogram hatching rate (HR) telur ikan tawes (B. gonionotus)

\section{Kualitas air}

Selama proses penelitian dilakukan pengukuran kualitas air diantaranya adalah suhu, $\mathrm{pH}$ dan oksigen terlarut (DO). Hasil pengukuran kualitas air tersaji pada Tabel 2.

Tabel 2. Hasil Parameter Kualitas Air Penetasan Telur Ikan Tawes (B.gonionotus)

\begin{tabular}{ccc}
\hline Variabel & Nilai Terukur & Nilai Kelayakan (Pustaka) \\
\hline Suhu & $26-28^{0} \mathrm{C}$ & $25^{\circ} \mathrm{C}-33^{\circ} \mathrm{C} *$ \\
pH & 8 & $6,7-8,6^{* *}$ \\
DO & $2,5-3,0 \mathrm{mg} / 1$ & $3,6-6,0 \mathrm{mg} / 1^{* * *}$ \\
\hline
\end{tabular}

Keterangan:

*Sastrawibawa (2011)

**Evi (2001)

*** Ray (2013)

\section{PEMBAHASAN}

Perkembangan embrio (Embriogenesis)

Tahap-tahap perkembangan embriogenesis menjadi sebuah larva dimulai dari fase cleavage (pembelahan sel), morula, blastula (pembentukan blastoderm), gastrula (penutupan kantung kuning telur), organogenesis hingga embrio menetas dan keluar dari cangkang telur.

Fase morula

Pengamatan perkembangan embrio dimulai saat telur ikan tawes dimasukkan sesuai dengan wadah pengamatan telah memasuki fase morula pada menit ke 50. Sebelum fase morula terjadi yaitu terdapat fase pembelahan telur yang tidak terdeteksi dalam pengamatan karena proses yang sangat cepat. Menurut Pangreksa $e t$ al., (2016), bahwa perkembangan embrio terdiri dari beberapa tingkatan atau fase, yang pertama adalah fase pembelahan dari 2 (dua) sel sampai 64 sel. Kedua adalah fase blastula dengan pembelahan 128 sel sampai sekitar seribu sel. Ketiga adalah perisai embrio, kemudian yang ke-empat gastrula, ke-lima periode segmentasi dan yang terakhir adalah fase embrio menetas menjadi benih.

Fase morula dalam perkembangan embrio ikan dapat terlihat dengan jelas memiliki ciri sel dalam telur membelah. Pembelahan ke 32 sel dan membelah membentuk lapisan ke-2 di bagian kutub yang terlihat kurang jelas. Menurut Renita et al., (2016), bahwa fase morula ditandai dengan sel membelah secara melintang dan mulai terbentuk formasi lapisan kedua secara samar pada kutub anima. Fase morula berakhir apabila pembelahan sel sudah menghasilkan blastomer yang ukuran sama tetapi lebih kecil. Sel tersebut memadat untuk menjadi blastodisk kecil membentuk dua lapis sel.

\section{Fase blastula}

Fase blastula pada perlakuan C dan D terjadi pada menit ke 170 sampai 230 dan pada perlakuan A dan B terjadi pada menit ke 230 sampai 350. Ciri fase blastula yaitu pada lapisan kedua telur lebih memadat dibanding 


\section{Z.Alfath, F. Basuki, R.A. Nugroho/Jurnal Sains Akuakultul Tropis:4(2020)2:129-138 eISSN:2621-0525}

dengan fase morula. Menurut Renita et al., (2016), pada akhir fase blastula, sel-sel blastoderma akan terdiri dari neural, epidermal, notochordal, mesodermal serta endodermal yang merupakan bakal pembentuk organ-organ.

Ukuran sel dalam fase blastula terlihat semakin kecil dan menipis. Daerah sekeliling sel terlihat seperti cincin dengan bagian tengah kosong. Menurut Ardhariansyah et al., (2017), bahwa fase blastula terjadi saat embrio terus melakukan pembelahan sel untuk berkembang menjadi blastula, yaitu ditandai dengan terbentuknya rongga kosong. Selama stadia blastula, blastomer membelah beberapa kali membentuk blastomer-blastomer dengan ukuran yang makin kecil, sehingga tempat pada stadia morula blastomer semula padat akan terbentuk ruangan kosong yang disebut blastosul yang ditutupi oleh blastoderm dan pada sisi luar terdapat epiblast. Antara blastosul dan blastoderm dipisahkan oleh hypoblast primer.

\section{Fase gastrula}

Fase gastrula pada perlakuan C dan D terjadi pada menit ke 290 sampai 350, sedangkan perlakuan B di menit 410 dan perlakuan A di menit 410 sampai 470 . Fase gastrula ditandai dengan pada awal fase ini blastoderma menutupi hampir seluruh kuning telur. Bagian yang tidak menutupi kuning telur dinamakan blastopor. Menurut Nawir et al., (2016), bahwa stadium gastrula pada ikan diawali dengan penebalan di tepi luar blastodik, sehingga terbentuk suatu lingkaran berbentuk seperti cincin yang di sebut cincin kecambah (germ ring). Cincin kecambah posterior yang lebih tebal disebut perisai cincin kecambah (embryonic shield).

Perubahan ciri pada fase gastrula terlihat jelas yaitu adanya pergerakan sel yang memutar. Fase gastrula merupakan awal mula terbentuknya organ-organ larva ikan tawes. Menurut Farida et al., (2016), bahwa pada awal fase ini blastoderma menutupi hampir seluruh kuning telur. Bagian yang tidak menutupi kuning telur dinamakan blastopor. Jaringan luar embrio terus berkembang mengelilingi kuning telur. Setelah jaringan menutupi seluruh kuning telur terbentuklah perisai embrio pada kutub anima. Perisai embrio yang berada pada kutub anima akan berkembang menjadi tulang belakang. Akhir dari proses gastrulasi apabila kuning telur sudah tertutup lapisan sel (perisai embrio). Bersamaan dengan selesainya proses gastrulasi sebenarnya sudah dimulai awal pembentukan organ-organ.

\section{Organogenesis}

Fase organogenesis perlakuan $C$ dan $D$ terjadi secara bersamaan pada menit ke 410 , selanjutnya perlakuan B pada menit ke 470 dan perlakuan A menit ke 530. Bentuk embrio pada fase organogenesis telah menyerupai larva dengan bagian tubuh yang nampak lurus. Fase ini telah terbentuk organ bintik mata. Menurut Ardhardiansyah et al., (2017), bahwa terjadinya organogenesis, diawali dengan terbentuknya bakal kepala dan ekor, ruas-ruas tulang belakang, bakal mata, otolith, jantung, dan organ-organ lainnya, pigmentasi kantung kuning telur dan penetasan menghasilkan larva. Proses organogenesis ini berlangsung lebih lama dibanding dengan stadia-stadia lainya. Hasil pengamatan terhadap embrio selama fase organogenesis menunjukkan adanya pergerakan dari embrio. Pergerakan embrio ini diakibatkan oleh bertambah panjangnya bagian ekor embrio dan mulai terlepas dari kuning telurnya serta terdeteksi jantung sudah mulai aktif. Selain itu, penampakan dari notokorda dan somit makin jelas serta lekukan pada kepala sudah mulai Nampak. Proses penetasan embrio ikan terjadi bila embrio ukuran embrio lebih panjang dari diameter cangkangnya.

Bagian organ-organ yang terbentuk pada fase organogenesis meliputi sistem syaraf, jantung, mata, ruas tulang belakang, ekor dan lain-lain. Terbentuknya bakal organ tersebut akan berlangsung sampai telur menetas dengan sempurna Menurut Renita et al., (2016), bahwa fase organogenesis merupakan tahap pembentukan organ pada embrio. Dalam fase organogenesis terbentuk berturut-turut bakal organ yaitu syaraf, notochord, mata, somit, rongga kuffer, kantong alfaktori, rongga ginjal, usus, tulang subnotochord, linealateralis, jantung, aorta, insang, infundibullum, dan lipatan-lipatan sirip.

\section{Lama waktu penetasan}

Berdasarkan hasil pengamatan lama waktu penetasan telur ikan tawes (B. gonionotus) di dapatkan waktu penetasan telur (menit) secara bersamaan yaitu pada perlakuan C dan D pada menit ke 470 telah mengalami organogenesis. Perkembangan telur rata-rata pada setiap perlakuan secara bersamaan yaitu terjadi di awal fase morula sampai dengan menit ke 230 fase blastula. Selanjutnya pada menit ke 290, perlakuan A dan B mulai berbeda dengan perlakuan C dan D. Perlakuan A dan B pada fase blastula, sedangkan untuk perlakuan C dan D telah memasuki fase gastrula. Perlakuan $\mathrm{C}$ dan $\mathrm{D}$ mengalami proses organogenesis bersamaan pada menit ke 410, sementara untuk perlakuan B organogenesis mulai terbentuk pada menit ke 470 dan untuk perlakuan A lebih lambat dari perlakuan lainnya yaitu pada menit ke 530.

Proses perkembangan telur ikan tawes berpengaruh terhadap lama waktu penetasan telur. Diketahui bahwa pada perlakuan $\mathrm{C}$ dan $\mathrm{D}$ secara bersamaan menghasilkan waktu penetasan paling cepat dibandingkan 


\section{Z.Alfath, F. Basuki, R.A. Nugroho/Jurnal Sains Akuakultul Tropis:4(2020)2:129-138 eISSN:2621-0525}

perlakuan B dan perlakuan A untuk telur ikan tawes menetas. Di awal fase perkembangan telur pada setiap perlakuan tidak tampak perbedaan yang signifikan. Waktu penetasan telur merupakan fase-fase perkembangan telur hingga menetasnya telur. Selama proses penetasan telur ikan terdapat aktivitas yang mempengaruhinya sehingga dapat berpengaruh terhadap lama waktu penetasan selain kepadatan yang berbeda. Menurut Blaxter (1969), menyatakan bahwa selama penginkubasian telur, aktivitas-aktivitas yang terjadi dalam telur lebih dipengaruhi oleh kondisi lingkungan terutama suhu, selain itu juga dipengaruhi oleh $\mathrm{pH}$, karbondioksida, intensitas cahaya, dan penyerapan oksigen.

Kepadatan telur yang berbeda mempengaruhi laju waktu penetasan telur pada setiap perlakuan. Perbedaan waktu penetasan telur disebabkan oleh perbedaan suhu media penetasan. Suhu menentukan ciri morfologis, laju penetasan dan tingkah laku ikan sewaktu menetas. Hal ini juga diperkuat oleh Andriyanto et al. (2013), bahwa perubahan suhu sangat berpengaruh terhadap perkembangan embrio karena mempengaruhi kecepatan metabolisme embrio. Suhu mengurangi aktivitas metabolisme dari sel sehingga akan menghambat perkembangan telur.

\section{Derajat penetasan (HR)}

Berdasarkan hasil nilai derajat penetasan (HR) telur ikan tawes (B. gonionotus) secara keseluruhan menunjukkan bahwa presentase penetasan dari nilai tertinggi hingga terendah dicapai oleh perlakuan B sebesar $89,83 \pm 3,55$, kemudian berturut-turut pada perlakuan A sebesar 86,33 $\pm 3,79$, perlakuan C sebesar $83,00 \pm 2,43$, dan perlakuan D sebesar 82,10 $\pm 1,39$.

Hasil uji duncan didapatkan bahwa perlakuan A tidak berbeda nyata dengan semua perlakuan. Perlakuan B berbeda nyata dengan perlakuan $\mathrm{C}$ dan $\mathrm{D}$, sedangkan perlakuan $\mathrm{C}$ tidak berbeda nyata dengan perlakuan $\mathrm{D}$ dan sebaliknya. Dilihat dari segi angka tertinggi maka diperoleh perlakuan B sebagai perlakuan tertinggi dan terbaik dibandingkan dengan perlakuan lainnya, walaupun kepadatan pada perlakuan B lebih tinggi dibandingkan dengan perlakuan A. Telur-telur dalam setiap wadah perlakuan memiliki karakteristik dan kualitas yang berbeda. Kepadatan pada perlakuan B dengan tingkat kepadatan kedua terendah menghasilkan daya tetas yang tinggi dan berkualitas baik. Kualitas telur yang berbeda dalam setiap perlakuan dapat mempengaruhi derajat penetasan telur. Menurut Nur et al., (2009), bahwa daya tetas telur dipengaruhi oleh beberapa faktor antara lain kualitas telur itu sendiri, fertilitas telur terkait dengan kemampuan sperma membuahi sel telur serta kualitas air inkubasi. Daya tetas telur adalah kemampuan telur untuk berkembang dalam proses embriogenesis hingga telur menetas. Kualitas telur yang baik memiliki kandungan asam amino dan asam lemak dalam jumlah yang cukup.

Kepadatan yang berbeda dalam setiap perlakuan memiliki pengaruh yang cukup signifikan terhadap derajat penetasan telur ikan tawes. Perlakuan dengan kepadatan yang menengah memiliki nilai daya tetas telur yang tinggi dibanding dengan perlakuan kepadatan yang paling rendah dan tinggi. Hal tersebut dikarenakan pada proses penetasan telur terjadi perkembangan kerja mekanik yang mempengaruhi setiap telur untuk menetas. Hasil tmenunjukan bahwa dengan kepadatan tertinggi telur ikan tawes akan semakin cepat menetas, tetapi derajat penetasan telur ikan tawes semakin rendah. Menurut Redha et al. (2015), penetasaan terjadi karena kerja mekanik, oleh embrio sering mengubah posisinya karena kekurangan ruangan dalam cangkanganya. Dengan pergerakan pergerakan tersebut bagian telur lembek dan tipis akan pecah sehingga embrio akan keluar dari cangkangnya, kerja enzimatik, yaitu enzim dan zat kimia lainnya yang dikeluarkan oleh kelenjar endodermal di daerah pharink embrio. Enzim ini disebut chorionase yang kerjanya bersifat mereduksi chorion yang terdiri dari pseudokeratine menjadi lembek. Sehingga pada cangkang yang tipis dan terkena chorionase akan pecah dan ekor embrio keluar dari cangkang kemudian diikuti tubuh dan kepalanya.

Derajat penetasan telur ikan tawes dengan pengaruh kepadatan yang berbeda juga dapat dipengaruhi oleh faktor luar seperti kualitas air dalam wadah penetasan. Menurut Putri et al., (2013), menyatakan bahwa daya tetas telur yang rendah dipengaruhi oleh faktor internal dan faktor eksternal. Faktor internal dapat dipengaruhi oleh indukan, sehingga terjadi pembuahan telur yang tidak sempurna. Faktor eksternal dapat dipengaruhi oleh kualitas air. Kematian telur juga dapat terjadi karena embrio tidak mampu melakukan metabolisme. Menurut Hardaningsih et al., (2008), faktor lingkungan seperti suhu, salinitas dan oksigen terlarut dapat mempengaruhi derajat penetasan. Menipisnya lapisan lendir pada telur mengakibatkan banyak pori-pori telur terbuka untuk proses keperluan pernafasan pada telur, sehingga hal tersebut dapat meningkatkan derajat penetesan telur pada ikan.

\section{Kualitas Air}

Pengamatan kualitas air pada wadah pemeliharaan telur ikan tawes meliputi pengukuran oksigen terlarut (DO), suhu dan pH. Pengukuran dilakukan pada awal dan akhir selama penelitian. Kualitas air pada media 


\section{Z.Alfath, F. Basuki, R.A. Nugroho/Jurnal Sains Akuakultul Tropis:4(2020)2:129-138 eISSN:2621-0525}

pemeliharaan dapat menunjang bagi proses penetasan dan kehidupan ikan sebagai bagian dari keseimbangan fisiologis ikan budidaya.

Kadar oksigen terlarut dalam wadah penetasan telur ikan tawes selama penelitian berkisar antara 2,5 $3,0 \mathrm{mg} / \mathrm{l}$, hal tersebut dapat dikatakan kurang layak bagi penetasan telur dan pemeliharaan benih ikan tawes Menurut Rosmawati dan Muarif (2010), Rendahnya kandungan oksigen dapat menyebabkan kematian. Kisaran oksigen terlarut yang tidak membahayakan kehidupan ikan adalah 5,7 - 6,4 mg/l untuk kelangsungan hidup dan pertumbuhan ikan.

Berdasarkan hasil pengukuran suhu selama penelitian didapatkan suhu dalam keadaan normal sesuai dengan tempat penelitian yaitu berkisar $26-28^{\circ} \mathrm{C}$. Suhu media pemeliharaan secara umum dapat dikatakan layak bagi penetasan dan pemeliharaan benih ikan. Menurut Hutagalung et al., (2010), menyatakan bahwa suhu merupakan faktor penting yang mempengaruhi sekresi enzim penetasan. Pada suhu rendah, pemijahan dan penetasan akan terhambat, juga mengurangi sintasan. Sebaliknya, embrio dari suhu rendah dipindahkan ke medium dengan suhu yang lebih tinggi akan mempercepat penetasannya dan meningkatkan derajat penetasan. Suhu yang lebih tinggi juga menyebabkan selaput telur lebih cepat larut dibandingkan pada suhu rendah sehingga waktu penetasan pun lebih cepat. Ikan tawes dapat hidup dengan suhu optimum antara $25^{\circ} \mathrm{C}-33^{\circ} \mathrm{C}$ dan suhu minimal berkisar $15^{\circ} \mathrm{C}$ (Sastrawibawa, 2011).

Nilai derajat keasaman $(\mathrm{pH})$ selama penelitian yaitu stabil dikisaran 8. Hal tersebut dapat dikatakan layak bagi penetasan telur ikan tawes. $\mathrm{pH}$ yang terlalu tinggi dapat mempengaruhi kinerja metabolisme tubuh ikan sehingga dapat mempengaruhi kondisi ikan untuk pertumbuhan ikan tawes yaitu $\mathrm{pH}$ dalam air 6,8-7,8. $\mathrm{pH}$ menurun jika kepadatan ikan meningkat, hal ini karena pembentukan $\mathrm{CO}_{2}$ selama respirasi akan meningkat sehingga $\mathrm{pH}$ menurun.

\section{KESIMPULAN}

Kesimpulan yang dapat diambil dari hasil penelitian adalah sebagai berikut :

1. Kepadatan telur ikan tawes yang berbeda pada media penetasan memberi pengaruh terhadap embriogenesis dan lama waktu penetasan dan berpengaruh nyata terhadap derajat penetasan (HR) telur ikan tawes.

2. Kepadatan telur pada perlakuan $\mathrm{C}$ dan $\mathrm{D}$ secara bersamaan menghasilkan waktu penetasan terbaik dan perlakuan B menghasilkan derajat penetasan terbaik yaitu $89,83 \pm 3,55$.

\section{UCAPAN TERIMA KASIH}

Terima kasih penulis ucapkan kepada Satuan Kerja Perbenihan dan Budidaya Ikan Air Tawar (PBIAT) Ngrajek, Magelang, Jawa Tengah.

\section{DAFTAR PUSTAKA}

Andriyanto A, Bejo S, I Made DJA. 2013. Perkembangan Embrio dan Rasio Penetasan Telur Ikan Kerapu Raja Sunu (Plectropoma Laevis) pada Suhu Media Berbeda. Jurnal Ilmu dan Teknologi Kelautan Tropis 5(1): 192-203.

Agustin, F. dan B.S. Rahardja. 2013. Teknik Pembenihan Ikan Tawes (Puntius javanicus) dengan Sistem Induksi di Balai Perbenihan dan Budidaya Ikan Air Tawar Muntilan, Kecamatan Muntilan, Kabupaten Magelang. J. Aquaculture and Fish Health. Vol. 2(2)

Ardhardiansyah. 2017. Embriogenesis dan Karakteristik Larva Persilangan Ikan Patin Siam (Pangasius hypophthalmus) Jantan dengan Ikan Baung (Hemibagrus nemurus) Betina. J. Perikanan dan Kelautan Vol. 7 (2): 17-27

Blaxter, J.H.S. 1969. Development : Eggs and Larva in Fish Physiology, Vol III Reproduction and Growth, Bioluminescent, Pigmen and Poisons. Academic Press. New York.

Evi, R. 2001. Usaha Perikanan di Indonesia. Penerbit Mutiara Sumber Widya, Jakarta, $150 \mathrm{hlm}$

Hadid, Yanal, M. Syaifudin, dan M. Amin. 2014. Pengaruh Salinitas Terhadap Daya Tetas Telur Ikan Baung (Hemibagrus nemurus Blkr.). Jurnal Akuakultur Rawa Indonesia, 2(1) :78-92

Hanief, M.A. Rifqi, Subandiyono dan Pinandoyo. 2014. Pengaruh Frekuensi Pemberian Pakan Terhadap Pertumbuhan dan Kelulushidupan Benih Tawes (Puntius javanicus). Journal of Aquaculture Management and Technology. 3(4): 67-74

Hardaningsih, Sukardi dan T. Rochmawatie. 2008. Pengaruh Fluktuasi Suhu Air Terhadap Daya Tetas Telur dan Kelulushidupan Larva Gurame (Osphronemus gouramy). J. Akuakultur Indonesia. Vol. 9(1):55-60 


\section{Z.Alfath, F. Basuki, R.A. Nugroho/Jurnal Sains Akuakultul Tropis:4(2020)2:129-138 eISSN:2621-0525}

Hepher, B dan Y. Pruginin. 1981. Comemrcial Fish Farming: With Special Reference to Fish `Culture In Israel. John Wiley and Sons. New York.

Hutagalung, Junita, H. Alawi dan Sukendi. 2010. Pengaruh Suhu dan Oksigen Terhadap Penetasan Telur dan Kelulushidupan Awal Larva Ikan Pawas (Osteochilus hasselti C.V.). Universitas Riau

Nawir, Sukendi dan Nuraini. 2016. The Embryonic of Pawas (Osteochilus hasselti C.V) with Different Temperature. Universitas Riau

Nur, Bastian Chumaidi, Sudarto, L. Pouyaud dan J. Slembrouck. 2009. Pemijahan dan Perkembangan Embrio Ikan Pelangi (Melanotaenia spp.) Asal Sungai Sawiat, Papua. J. Ris. Akuakultur 4(2):147-156

Pangreksa, Amelia, Mustahal, F.R. Indaryanto dan B. Nur. 2016. Pengaruh Perbedaan Suhu Inkubasi Terhadap Waktu Penetasan dan Daya Tetas Telur Ikan Sinodontis (Synodontis eupterus). Jurnal Perikanan dan Kelautan. Vol.6(2): $147-160$

Putri, Dwi A., Muslim dan Mirna Fitrani. 2013. Persentase Penetasan Telur Ikan Betok (Anabas testudineus) dengan Suhu Inkubasi yang Berbeda. Jurnal Akuakultur Rawa Indonesia, 1(2) :184-19

Ray, A. K. 2013. Feasibility of Cage Culture of Exotic Carp Barbonymus gonionotus (Bleeker, 1850) in Composite Fish Farming Systems. [thesis]. Department of Aquatic Environment Management Faculty Of Fishery Sciences West Bengal University of Animal and Fishery Sciences 5 - Budherhat Road, Chakgaria, P.O. Panchasayar, Kolkata-94

Redha, A.Rasyid, E.I. Rahardjo dan Hastiadi Hasan. 2014. Pengaruh Suhu yang Berbeda Terhadap Perkembangan Embrio dan Daya Tetas Telur Ikan Kelabau (Osteochilus melanopleura). Jurnal Ruaya Vol.4

Renita, Rachimi dan E.I. Raharjo. 2016. Pengaruh Suhu Terhadap Waktu Penetasan, Daya Tetas Telur dan Kelangsungan Hidup Larva Ikan Cupang (Betta splendens). Universitas Muhammadiyah Pontianak

Rosmawati dan Muarif. 2010. Kelangsungan Hidup dan Pertumbuhan Benih Ikan Lele Dumbo (Clarias sp.) pada Sistem Resirkulasi dengan Kepadatan Berbeda. Jurnal Sains Akuatik. Vol. 13 (2):1 -8

Rustidja, 1997. Pembenihan Ikan-Ikan Tropis. Fakultas Perikanan Universitas Brawijaya. Malang.

Sastrawibawa, 2011. Teknologi Produksi Ikan Tawes (Puntius javanicus blkr) Diploid dan Haploid. Unpad Press. Bandung. 165 hal.

Sinjal, H. 2011. Pengaruh Substrat Ijuk dan Hydrilla sp. terhadap Derajat Pembuahan dan Penetasan Telur Ikan Mas. Jurnal Perikanan dan Kelautan Tropis.7 (1): 32-35

Srigandono, B. 1992. Rancangan Percobaan. Fakultas Peternakan. Universitas Diponegoro. Semarang (Untuk Kalangan Sendiri). $128 \mathrm{hlm}$.

Sugihartono, Muhammad. 2013. Respon Tingkat Kepadatan Telur Ikan Gurami (Osphronemus gouramy. Lac.) yang Berbeda Terhadap Daya Tetas Telur. J. Ilmiah Batanghari Jambi. Vol.13(4)

Vladimirov. 1975. Critical period in Developmen of Fishes. Journal of Ichtiology, 15 (6). 51 - 53 